\title{
The Alkaline Hydrolysis of isoPropoxy-methyl-phosphoryl Fluoride (Sarin) and some Analogues
}

\author{
LE N N A R T L A R S O N
}

\author{
Research Institute of National Defence, Dept. 1, Sundbyberg 4, Sweden
}

\begin{abstract}
The alkaline hydrolysis of Sarin and ten analogues have been studied at different temperatures with an electrometric method. The bimolecular rate constants and the energies and entropies of activation of the reactions have been calculated. The hydrolysis products have been examined with paper chromatographic technique. The results indicate that the hydrolysis proceeds as an one-stage reaction $\left(S_{N} 2\right)$ and involves a nucleophilic attack of the hydroxyl ion on the phosphorus atom. The attraction between them is controlled by the inductive and mesomeric effects of the substituents which also influence the strength of the $\mathrm{P}-\mathrm{F}$ bond. On the basis of the theories of Kirkwood and Westheimer a semi-quantitative treatment of the electrostatic effects of the substituents on the rates has been performed, and a fairly good agreement between calculated and found rate constants has been obtained.
\end{abstract}

Since the fundamental investigation of the hydrolysis of di-isopropoxy$N_{\text {phosphoryl fluoride, DFP, performed by Kilpatrick }}{ }^{1}$, several papers concerning different reactions of fluorine derivatives of organic phosphorus compounds have been published. Especially the reactions of Sarin and of DFP with catechols ${ }^{2,3}$, hydroxamic acids ${ }^{4,5}$ and oximes ${ }^{6}$ have attracted attention. The hydrolysis of Sarin catalyzed by hydroxyl ions has also been touched in some papers ${ }^{4,7}$.

Sarin has caught interest because of its potent effects on the cholinergic transmission. It has also been considered as a potential war gas. The hydrolysis of Sarin is thus of practical importance for chemical and pharmacological studies as well as for its decontamination. The purpose of this investigation was to determine the $\mathrm{pH}$-dependence of the hydrolysis of Sarin and to elucidate the reaction mechanism of its alkaline hydrolysis. It was also of interest to study the effect of substituents on the rates of hydrolysis of compounds with the general formula

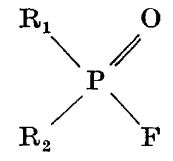

Acta Chem. Scand. 11 (1957) No. 7 
Because the hydrolysis of Sarin as well as the hydrolysis of its analogues is catalyzed by several ions, it is rather complicated to study the $\mathrm{pH}$-dependence of the reaction in various buffer solutions. The hydrolysis has instead been studied by an electrometric method developed by Larsson and Hansen ${ }^{8}$. The nomenclature used in this paper conforms to the Swedish proposition ${ }^{9}$.

\section{EXPERIMENTAL}

Materials. The methyl-fluoro-phosphorylcholine derivatives were synthesized in this institute by Tammelin ${ }^{10}$. The other organic phosphorus compounds except the bromoethoxy-and dimethylbutoxy-derivatives were synthesized by Tammelin and Fagerlind ${ }^{11}$. 2-Bromoethoxy-methyl-phosphoryl fluoride and 3,3-dimethylbutoxy-methyl-phosphoryl fluoride were synthesized by reacting methyl-fluoro-phosphoryl chloride with 2-bromoethanol and 3,3-dimethylbutanol ${ }^{12}$, respectively, according to the scheme given by Tammelin ${ }^{10}$. Analytical data of these two compounds are shown in Table 1. The densities, determined with a self-filling pycnometer ${ }^{13}$, and refractive indices of the liquid compounds as well as the formulae of all the compounds are given in Table 2. Methylphosphoryl-dichloride used in the chromatographic study was prepared according to Kinnear and Perren ${ }^{14}$. The salts were recrystallized and the liquids freshly distilled before use.

Paper chromatographic technique. The phosphorus compounds to be chromatographed were hydrolyzed in $0.1 \mathrm{M}$ ammonium hydroxide. The choline chloride used was dissolved in distilled water. Five $\mu \mathrm{l}$ of $0.5 \%$ solutions of the compounds were placed with micropipettes on a filter paper, Whatman No. 1, Ascending technique was used, and the chromatograms were run at $25^{\circ} \mathrm{C}$. Both acid and alkaline solvents were tested. The composition of the acid solvent was: $n$-butanol : ethanol : acetic acid : water $(8: 2: 1: 3)^{15}$, and that of the alkaline solvent was: tert.-butanol : isopropanol : $2 \mathrm{M}$ ammonium hydroxide $(2: 2: 1)$.

The development of the spots from the phosphorus compounds was carried out by spraying the paper with an acid solution of ammonium molybdate and treating the dried paper with hydrogen sulfide ${ }^{16}$.

An attempt to develop the chromatographed hydrolyzate of one of the phosphorylcholine derivatives in respect of the choline group was made in three different ways: by spraying with a solution of dipicrylamine ${ }^{15}$, by immersing in a solution of Reinecke salt ${ }^{17}$, and by immersing in a solution of phosphomolybdic acid with subsequent reduction with stannous chloride ${ }^{18}$. Choline chloride was developed with dipicrylamine.

Kinetic measurements. The rates of the hydrolysis of the compounds were studied by means of an automatic recording titrator ${ }^{8}$. The principle of this instrument is that acid products formed in the hydrolysis are neutralized by addition of alkali in such a rate

Table 1. Analytical data.

\begin{tabular}{|c|c|c|c|c|c|c|c|c|c|}
\hline \multirow{2}{*}{ Compound } & \multirow{2}{*}{ Formula } & \multirow{2}{*}{ 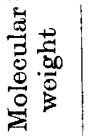 } & \multicolumn{2}{|c|}{$\% \mathrm{C}$} & \multicolumn{2}{|c|}{$\% \mathrm{H}$} & \multicolumn{2}{|c|}{$\% \mathrm{Br}$} & \multirow{2}{*}{$\begin{array}{l}\text { B.p. } \\
{ }^{\circ} \mathrm{C} / \mathrm{mm} \\
\mathrm{Hg}\end{array}$} \\
\hline & & & calc. & found & cale. & found & calc. & found & \\
\hline $\begin{array}{l}\text { 2-Bromoethoxy-methyl- } \\
\text { phosphoryl fluoride }\end{array}$ & $\mathrm{C}_{3} \mathrm{H}_{7} \mathrm{BrFO}_{2} \mathrm{P}$ & 205.0 & 17.6 & 17.9 & 3.4 & 3.4 & 39.0 & 38.9 & $58 / 0.7$ \\
\hline $\begin{array}{l}\text { 3,3-Dimethylbutoxy- } \\
\text { methyl-phosphoryl fluo- } \\
\text { ride }\end{array}$ & $\mathrm{C}_{7} \mathrm{H}_{16} \mathrm{FO}_{2} \mathrm{P}$ & 182.2 & 46.1 & 45.7 & 8.9 & 8.9 & - & - & $50 / 0.5$ \\
\hline
\end{tabular}

Acta Chem. Scand. 11 (1957) No. 7 
Table 2. The formulae, densities and refractive indices of the organic phosphorus compounds studied.

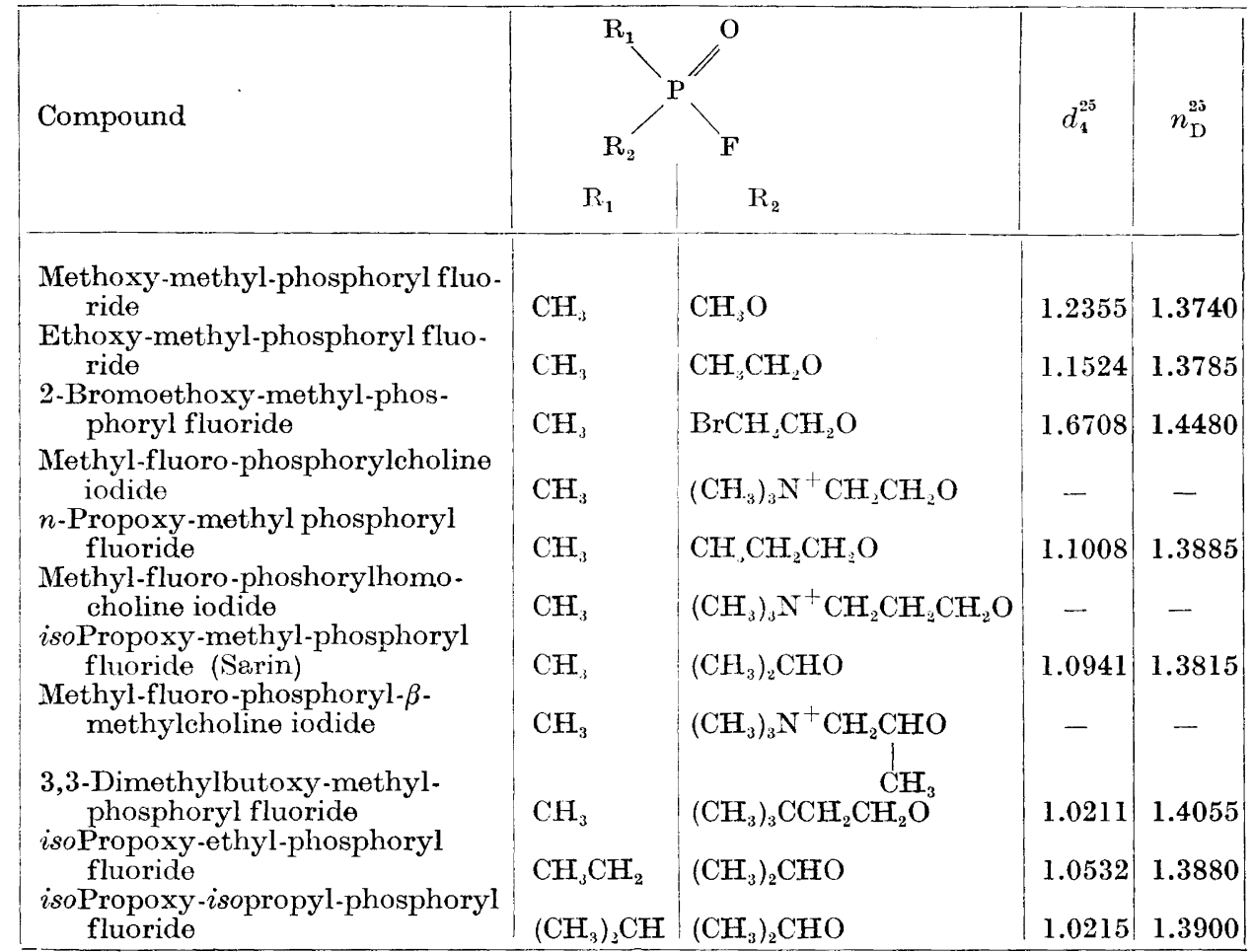

that the $\mathrm{pH}$ is maintained constant in the reaction mixture. The volume of the alkali added is recorded as a function of time. The instrument is based on a Radiometer Titrator, Type TTT1. A Radiometer glass electrode, Type G 202 A, was used as indicator electrode, and a saturated calomel electrode with diffusion filter, Type K 300, as reference electrode. At $\mathrm{pH}$ values above 9.00 a special glass electrode, Type G $202 \mathrm{~B}$, was used. During the reaction the fluctuation of $\mathrm{pH}$ was generally less than $\pm 0.02 \mathrm{pH}$-units. A constant temperature circulating water bath maintained the jacketed reaction vessel at $\pm 0.1^{\circ} \mathrm{C}$ or better.

The $\mathrm{pH}$-meter was standardized before each run against $0.05 \mathrm{M}$ solution of potassium hydrogen $o$-phthalate and $0.01 \mathrm{M}$ solution of sodium tetraborate. The $\mathrm{pH}$-values of the standard buffer solutions at different temperatures appear in Table 3 as well as the values of the ion product of water, $\mathrm{pK}_{w}{ }^{19}$, used in the calculation of $\mathrm{pOH}$ at the different temperatures. In the same table and in Table 5 the activity coefficients of hydroxyl ions, $\mathrm{oH}^{-}$, are also given. The activity coefficients of hydroxyl ions were estimated from the Hückel equation:

$$
-\log f_{\mathrm{OH}^{-}}=\frac{A z_{\mathrm{OH}^{-}}^{2} \sqrt{\mu}}{1+B r_{\mathrm{OH}^{-}}-\sqrt{\mu}}-C \mu
$$

The values of $A$ and $B$ at different temperatures have been reported by Manov et al. ${ }^{20}$. The effective radius of the hydroxyl ion, $\mathrm{roH}^{-}$, was taken to be $3.5 \AA$. The coefficient $C$ was given the value 0.020 , which is used in the calculation of the mean activity coefficient

Acta Chem. Scand. 11 (1957) No. 7 
Table 3. The $\mathrm{pH}$ values of the standard buffer solutions, the ion products of water, $\mathrm{p} K_{w}$, and activity coefficients of hydroxyl ions, $f_{\mathrm{OH}^{-}}$, at different temperatures.

\begin{tabular}{|c|c|c|c|c|}
\hline$t^{\circ} \mathrm{C}$ & $\begin{array}{c}|c| \\
0.05 \mathrm{M} \text { potassium } \\
\text { hydrogen phthalate }\end{array}$ & $\begin{array}{c}0.01 \mathrm{M} \text { sodium } \\
\text { tetraborate }\end{array}$ & $\mathrm{p} K_{w}$ & $\begin{array}{c}t_{\mathrm{OH}^{-}} \\
\mu=0.100\end{array}$ \\
\hline & & & & \\
20 & 4.00 & 9.22 & 14.17 & 0.767 \\
25 & 4.01 & 9.18 & 14.00 & 0.766 \\
30 & 4.01 & 9.14 & 13.83 & 0.764 \\
35 & 4.02 & 9.10 & 13.68 & 0.762 \\
\hline
\end{tabular}

of potassium chloride; in dilute alkali solutions this value seems to be more reasonable to use than that given for potassium hydroxide ${ }^{21}$.

The choline derivatives were dissolved in abs. ethanol; the solutions were freshly prepared every day. The other compounds studied were dissolved in dioxan, E. Merck c.p., purified from peroxides and redistilled over sodium. The concentration of the compounds in the stock solutions were $10 \mathrm{mM}$. In the reaction vessel 1 to $2 \mathrm{ml}$ of the stock solution was diluted to $40.0 \mathrm{ml}$ with $0.100 \mathrm{M}$ solution of potassium chloride which before the addition of the stock solution had been adjusted to the desired $\mathrm{pH}$-value. The concentration of the sodium hydroxide added was $0.050 \mathrm{M}$. The slight dilution during the reaction due to the volume of the alkali was neglected. The potassium chloride solution was used to maintain the ionic strength eonstant. In one series of experiments the concentration of potassium chloride was varied and in one case sodium fluoride was used. The final concentrations of the compounds varied between 0.25 and $0.50 \mathrm{mM}$.

\section{RESULTS}

\section{Hydrclysis products}

When Sarin or its analogues studied in this paper are hydrolysed in alkaline solution exactly two equivalences of acid are formed. In the hydrolyzates - fluoride ion was indicated with zirkon alizarin paper.

The hydrolyzates of Sarin and of methyl-fluoro-phosphorylcholine were analysed with paper chromatographic technique to investigate the products which were formed. Only one spot indicating a phosphorus compound was obtained on the two chromatograms. As comparison solutions of methyldihydroxy-phosphine oxide, obtained from methylphosphoryl dichloride, and of choline chloride were analysed in the same manner. The $R_{F}$ value of the hydrolyzate of Sarin does not agree with that of methyl-dihydroxy-phosphine oxide. It is thus proved that this compound is not formed in the hydrolysis and that the hydrolysis product containing phosphorus must be methylisopropoxy-hydroxy-phosphine oxide. Neither the $R_{F}$ value of choline nor that of methyl-dihydroxy phosphine oxide agree with the $R_{F}$ value of the hydrolyzate of methyl-fluoro-phosphorylcholine. This indicates that these compounds are not formed in the hydrolysis, and that the hydrolysis product must be methyl-hydroxy-phosphorylcholine. The $R_{F}$ values of the four compounds in acid and alkaline solvents are given in Table 4. It is, however, remarkable that the choline group in methyl-hydroxy-phosphorylcholine was impossible to indicate with any of the three developers used for choline. 
Table 4. The $R_{F}$ values in acid and alkaline solvents.

\begin{tabular}{|l|c|c|}
\hline \multicolumn{1}{|c|}{ Compound } & \multicolumn{2}{|c|}{$R_{F}$} \\
& $\begin{array}{c}\text { Acid } \\
\text { solvent }\end{array}$ & $\begin{array}{c}\text { Alkaline } \\
\text { solvent }\end{array}$ \\
\hline & & \\
Methyl-dihydroxy-phosphine oxide & 0.26 & 0.02 \\
isoPropoxy-methyl-hydroxy-phosphine oxide & 0.64 & 0.48 \\
Methyl-hydroxy-phosphorylcholine & 0.22 & 0.18 \\
Choline chloride & 0.43 & 0.31 \\
\hline
\end{tabular}

These results indicate that the hydrolysis proceeds according to the following scheme:



and that any further hydrolysis of the reaction products does not seem to occur under the present conditions.

pH-Dependence of the hydrolysis of Sarin

The $\mathrm{pH}$-dependence of the hydrolysis of Sarin was studied at $25^{\circ} \mathrm{C}$ at the $\mathrm{pH}$-values $8.00,8.40,8.70,9.00,9.40$ and 9.80 and at $35^{\circ} \mathrm{C}$ at the $\mathrm{pH}$ values $8.30,8.68$ and 9.13 . The hydrolysis curves obtained from the recorder were treated according to the method given by Guggenheim ${ }^{22}$. Straight lines were obtained indicating that the hydrolysis proceeds as a first-order reaction when the $\mathrm{pH}$ is maintained constant. If the rate of the hydrolysis only depends upon the hydroxyl ion activity and the reaction with water molecules can be neglected, the $\mathrm{pH}$-dependence of the hydrolysis at constant ionic strength may be equated as

or in logarithmic form

$$
k_{1}=k_{2}^{\prime} \cdot a_{\mathrm{OH}^{-}}=k_{2}^{\prime} \cdot \frac{K_{w}}{a_{\mathrm{H}^{+}}}
$$

$$
\log k_{1}=\log k_{2}^{\prime}-\mathrm{pOH}
$$

where $k_{1}$ is the pseudo first-order rate constant, $k_{2}^{\prime}$ the second-order rate constant at constant ionic stregth and $K_{w}$ the ionic product of water.

When the logarithms of the pseudo first-order constants in sec.-1 obtained from three runs at each $\mathrm{pH}$ are plotted against $\mathrm{pOH}$, using the values of $\mathrm{p} K_{w}$ given in Table 3, straight lines are obtained as shown in Fig. 1. The equations of the two lines were calculated by the method of least squares, and were found to be:

$$
\begin{aligned}
& \log k_{1}=1.519-0.995 \times \mathrm{pOH} \text { at } 25^{\circ} \mathrm{C} \text {, and } \\
& \log k_{1}=1.731-0.995 \times \mathrm{pOH} \text { at } 35^{\circ} \mathrm{C} \text {. }
\end{aligned}
$$

Acta Chem. Scand. 11 (1957) No. 7 


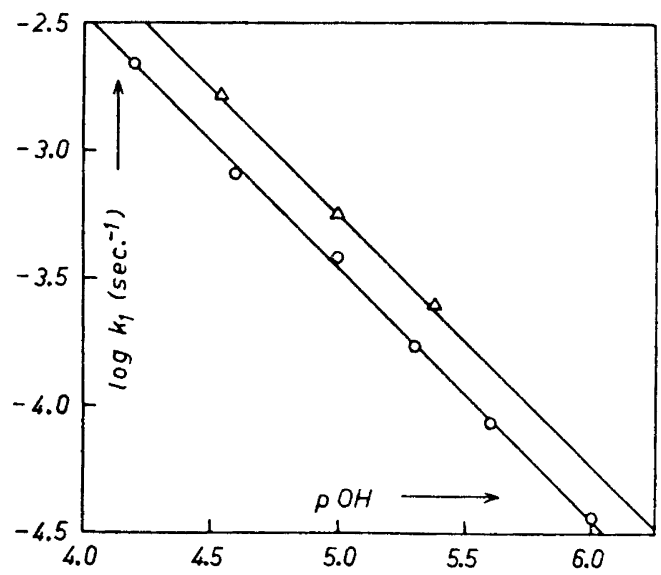

Fig. 1. The pOH dependence of the hydrolysis of Sarin $O$ at $25^{\circ} \mathrm{C}$ and $\triangle$ at $35^{\circ} \mathrm{C}$. The sizes of the points indicate the standard deviations in $\log k_{1}$.

The error in the found coefficients of $\mathrm{pOH}$ is \pm 0.013 and \pm 0.021 , respectively. The coefficients are within the limits of error equal to 1.00 which thus confirms the correctness of the proposed eqn. (2).

\section{Effect of ions on the hydrolysis of Sarin}

It appears from Table 5 that the rate of the hydrolysis of Sarin is increased when increasing the ionic strength at constant $\mathrm{pH}$. If, however, the secondorder rate constant, $k_{2}$, is calculated from the hydroxyl ion concentrations in question, this constant is found to be independent of the ionic strength within the limits of error. This will probably depend upon the activity coefficient of the hydroxyl ion canceling the activity coefficient of the charged activated complex and the activity coefficient of the uncharged Sarin molecule being unaffected in the ionic strength range in question. For that reason eqn. ( 2 a) has been transformed to the following equation:

$$
k_{1}=k_{2} \cdot c_{\mathrm{OH}^{-}}=k_{2} \cdot \frac{a_{\mathrm{OH}^{-}}}{f_{\mathrm{OH}^{-}}}
$$

where the bimolecular rate constant $k_{2}$ is independent of the ionic strength to at least 0.5 .

From Table 5 it is also shown that the fluoride ions have no effect on the the rate of the hydrolysis.

Temperaturedependence of the hydrolysis of Sarin and its an alogues

The temperature dependence of the hydrolysis of Sarin was determined at $20^{\circ} \mathrm{C}, 25^{\circ} \mathrm{C}, 30^{\circ} \mathrm{C}$ and $35^{\circ} \mathrm{C}$. The pseudo first-order rate constants obtained 
Table 5. The effect of ionic strength and fluoride ions on the hydrolysis of Sarin at $\mathrm{pH}$ 9.00 and $25^{\circ} \mathrm{C}$.

\begin{tabular}{|c|c|c|c|c|c|}
\hline $\mathrm{M}_{\mathrm{KCl}}$ & $\mathrm{M}_{\mathrm{NaF}}$ & $f_{\mathrm{OH}^{-}}$ & $c_{\mathrm{OH}^{-}} \times 10^{5}$ & $\begin{array}{c}k_{1} \times 10^{4} \\
\text { sec. }^{-1}\end{array}$ & $\begin{array}{c}k_{2} \\
1 \mathrm{~mole}^{-1} \text { sec. }^{-1}\end{array}$ \\
\hline 0.050 & - & 0.813 & 1.23 & 3.73 & 30.3 \\
0.100 & - & 0.766 & 1.31 & 3.81 & 29.1 \\
0.200 & - & 0.715 & 1.40 & 4.32 & 30.9 \\
0.500 & - & 0.649 & 1.54 & 4.42 & 28.7 \\
- & 0.100 & 0.766 & 1.31 & 3.83 & 29.2 \\
\hline
\end{tabular}

were converted into second-order rate constants by means of eqn. (3). The first-order rate constants at $20^{\circ} \mathrm{C}$ and $30^{\circ} \mathrm{C}$ were calculated from three runs at each temperature at $\mathrm{pH} 9.17$ and 8.83, respectively, i.e. at $\mathrm{pOH} 5.00$. The second-order rate constants at $25^{\circ} \mathrm{C}$ and $35^{\circ} \mathrm{C}$ were calculated from the results of the study of the $\mathrm{pH}$-dependence.

The Arrhenius activation energy, $E_{a}$, was calculated in usual manner by plotting $\log k_{2}$ against $1 / T$ as shown in Fig. 2. The line was drawn according to the method of least squares and the equation obtained was found to be

$$
\log k_{2}=8.049-1.979 \times 10^{3} 1 / T
$$

The value of the activation energy of Sarin obtained from this equation is given in Table 6.

In the same table there is also given the entropy of activation of the reaction, $\Delta S^{\neq}$; which is calculated according to Eyring ${ }^{23 a}$ for reactions in solution:

$$
k_{2}=\mathrm{e} \cdot \frac{k T}{h} \cdot \mathrm{e}^{-E a / R T} \cdot \mathrm{e}^{\Delta s^{\ddagger} / R}
$$

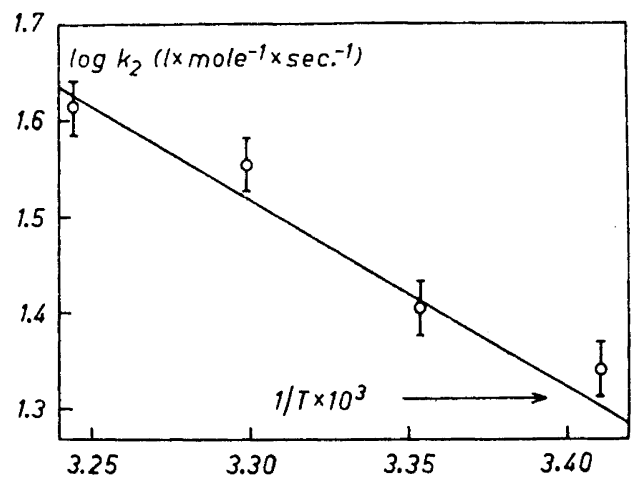

Fig. 2. The temperature dependence of the hydrolysis of Sarin. The values at $20^{\circ} \mathrm{C}$, $25^{\circ} \mathrm{C}, 30^{\circ} \mathrm{C}$ and $35^{\circ} \mathrm{C}$ are mean values of $3,18,9$ and 3 determinations, respectively. The lines through the points indicate the standard deviations in $\log k_{2}$.

Acta Chem. Scand. 11 (1957) No. 7 
Table 6. Rate constants and energies and entropies of activation of Sarin and its analogues.

\begin{tabular}{|c|c|c|c|c|c|c|c|c|}
\hline \multirow[b]{2}{*}{ Compound } & \multicolumn{2}{|c|}{$t=25^{\circ} \mathrm{C}$} & \multicolumn{2}{|c|}{$t=35^{\circ} \mathrm{C}$} & \multirow{2}{*}{\multicolumn{2}{|c|}{$\begin{array}{c}E_{a} \\
\operatorname{kcal} \cdot \mathrm{mole}^{-1}\end{array}$}} & \multirow{2}{*}{\multicolumn{2}{|c|}{$\begin{array}{l}\triangle S^{\ddagger} \\
\text { E.U. }\end{array}$}} \\
\hline & $\begin{array}{l}k_{1} \times 10^{4} \text { sec. }^{-1} \\
\mathrm{pOH}=5.50\end{array}$ & $\begin{array}{c}k_{2} \\
1 \mathrm{~mole}^{-1} \\
\text { sec. }^{-1}\end{array}$ & $\begin{array}{l}k \times 10^{4} \text { sec. }^{-1} \\
\mathrm{pOH}=5.50\end{array}$ & $\begin{array}{c}k_{2} \\
1 \mathrm{~mole}^{-1} \\
\text { sec. }^{-1}\end{array}$ & & & & \\
\hline $\begin{array}{l}\text { hoxy-methyl- } \\
\text { sphoryl fluoride }\end{array}$ & $\begin{array}{l}4.29 \\
4.53\end{array}$ & 106 & $\begin{array}{l}7.87 \\
7.77\end{array}$ & 188 & 10.5 & \pm 0.7 & -16 & \pm 2 \\
\hline $\begin{array}{l}\text { oxy-methyl- } \\
\text { sphoryl fluoride }\end{array}$ & $\begin{array}{l}2.45 \\
2.56\end{array}$ & 60.7 & $\begin{array}{l}4.77 \\
4.53\end{array}$ & 112 & 11.2 & \pm 0.8 & -15 & \pm 3 \\
\hline $\begin{array}{l}\text { romoethoxy-methyl- } \\
\text { sphoryl fluoride }\end{array}$ & $\begin{array}{l}6.74 \\
6.64\end{array}$ & 162 & $\begin{array}{l}12.6 \\
12.4\end{array}$ & 301 & 11.3 & \pm 0.3 & -13 & \pm 1 \\
\hline $\begin{array}{l}\text { hyl-fluoro-phosphoryl } \\
\text { ine iodide }\end{array}$ & $\begin{array}{l}38.8 \\
38.6\end{array}$ & 935 & $\begin{array}{l}20.2^{*} \\
20.0^{*}\end{array}$ & 1530 & 9.0 & \pm 0.2 & -17 & \pm 1 \\
\hline $\begin{array}{l}\text { ropoxy-methyl- } \\
\text { sphoryl fluoride }\end{array}$ & $\begin{array}{l}2.24 \\
2.22\end{array}$ & 54.0 & $\begin{array}{l}4.06 \\
3.82\end{array}$ & 95.3 & 10.4 & \pm 0.7 & -18 & $\doteq \mathbf{2}$ \\
\hline $\begin{array}{l}\text { hyl-fluoro-phospho- } \\
\text { homocholine iodide }\end{array}$ & $\begin{array}{l}12.5 \\
12.7\end{array}$ & 305 & $\begin{array}{l}24.1 \\
23.6\end{array}$ & 575 & 11.6 & \pm 0.4 & -10 & \pm 1 \\
\hline $\begin{array}{l}\text { ropoxy-methyl-phos- } \\
\text { cyl fluoride (Sarin) }\end{array}$ & - & 25.8 & - & 42.4 & 9.1 & +0.3 & -24 & \pm 1 \\
\hline $\begin{array}{l}\text { hyl-fluoro-phosphoryl- } \\
\text { thylcholine iodide }\end{array}$ & $\begin{array}{l}15.8 \\
15.6\end{array}$ & 381 & $\begin{array}{l}27.5 \\
27.5\end{array}$ & 663 & 10.1 & \pm 0.2 & -15 & \pm 1 \\
\hline $\begin{array}{l}\text { Dimethylbutoxy- } \\
\text { hyl-phosphoryl fluo- }\end{array}$ & $\begin{array}{l}2.05 \\
2.02\end{array}$ & 49.3 & $\begin{array}{l}3.88 \\
4.03\end{array}$ & 95.3 & 12.0 & \pm 0.6 & -13 & \pm 2 \\
\hline $\begin{array}{l}\text { ropoxy-ethyl- } \\
\text { sphoryl fluoride }\end{array}$ & $\begin{array}{l}1.20 \dagger \\
1.23 \dagger\end{array}$ & 9.35 & $\begin{array}{l}2.16 \dagger \\
2.24 \dagger\end{array}$ & 16.8 & 10.7 & \pm 0.6 & -20 & \pm 2 \\
\hline $\begin{array}{l}\text { ropoxy-isopropyl- } \\
\text { sphoryl fluoride }\end{array}$ & $\begin{array}{l}0.258 \dagger \\
0.272 \dagger\end{array}$ & 2.03 & $\begin{array}{l}0.443 \dagger \\
0.435 \dagger\end{array}$ & 3.35 & 9.2 & \pm 0.7 & -28 & \pm 2 \\
\hline
\end{tabular}

${ }^{*} \mathrm{pOH}=6.00 ; \dagger \mathrm{pOH}=5.00$

The pseudo first-order rate constants of the hydrolysis of the ten analogues to Sarin were determined at $25^{\circ} \mathrm{C}$ and $35^{\circ} \mathrm{C}$ and most of the experiments at $\mathrm{pOH} 5.50$; the most rapid hydrolyses were measured at $\mathrm{pOH} 6.00$ and the slowest ones at $\mathrm{pOH}$ 5.00. The values are shown in Table 6. The second-order rate constants were calculated on the presumption that the rate of the hydrolysis in conformity to the hydrolysis of Sarin is direct proportional to the hydroxyl ion concentration. This proved to be valid. for the hydrolysis of methylfluoro-phosphorylcholine within the limits of error, when the rates of hydrolysis were determined at $\mathrm{pOH} 5.50$ and $\mathrm{pOH} 6.00$ at $25^{\circ} \mathrm{C}$. From the rate constants obtained, the energy and entropy of activation of the ten Sarin analogues are calculated by means of Arrhenius' and Eyring's equations. The values of the second-order rate constants calculated from the mean values of the first order constants, and the energies and entropies of activation are given in Table 6 . The errors reported are maximum errors with the exception of those of Sarin which are the standard deviations. 


\section{DISCUSSION}

The direct proportionality of the reaction rate to the hydroxyl ion concentration in the hydrolysis of Sarin and its analogues indicates a bimolecular reaction mechanism. In the study of the hydrolysis of Tabun ${ }^{24}$ the author suggested the hypothesis that the hydrolysis proceeded as a two-stage reaction involving an intermediate like<smiles>[R12][P+]([R4])([Z])([O-])O</smiles>

formed by utilization of one of the vacant $3 d$ orbitals of phosphorus. If phosphorus shows such a tendency to expand its valence shell, it would be expected to coordinate the unshared electron pair on the nitrogen of ethoxydimethylaminoethoxy-methyl-phosphine oxide the formula of which can be designed:<smiles>CCOP1(C)([O-])OCC1(C)C</smiles>

If a bond of marked strength is established between the phosphorus and nitrogen atoms, this compound would be a considerably weaker base than the corresponding acetyl ester. Tammelin ${ }^{25}$ has, however, shown that the difference between their dissociation constants is relatively small $\left(\Delta \mathrm{p} K_{\mathrm{a}}=0.21\right)$ which indicates that no expansion of the valence shell of phosphorus occurs, and that only a weak bond of dipole-dipole character thus may be formed. This contradicts the hypothesis of the formation of an intermediate in the hydrolysis of Sarin and its analogues and favours a simple one-stage displacement mechanism $\left(S_{N} 2\right)$. Dostrovsky ${ }^{26}$ has also come to the same conclusion from his study of the hydrolysis of ${ }^{18} \mathrm{O}$-labelled diethoxy-phosphoryl chloride.

The low effect of the ionic strength as well as the negligible effect of the fluoride ion concentration exclude a $S_{N} 1$ mechanism and support the $S_{N} 2$ mechanism. The alkaline hydrolysis can thus be described with the usual bimolecular scheme:



A polarimetric examination of the hydrolysis of one of the optical isomers of for example methyl-fluoro-phosphorylcholine is likely to give further evidence of the mechanism. The proposed mechanism would thus lead to inversion of the configuration without racemization.

Acta Chem. Scand. 11 (1957) No. 7 
The influence of the substituents on the rate of hydrolysis has been discussed on the basis of the theory of the inductive and mesomeric effects of the substituents (Ingold's terminology) and on the presumption that the reaction involves a nucleophilic attack of the hydroxyl ion on the phosphorus atom which will carry a small positive charge. A change from methyl to isopropyl in the alkyl or akoxy group involves a decrease in the rate of the hydrolysis as appears from Table 6 . This can be explained by the increasing positive inductive effect, i.e. electron-releasing effect, when passing from methyl to isopropyl. This effect tends to increase the electronic density of the phosphorus atom and in this way to diminish the attraction of the hydroxyl ion. The decrease in rate is especially pronounced in the variation of the alkyl group. The low values of entropy of activation in these cases indicate a decreased probability of the transition state caused by steric hindrance. A substitution of hydrogen in the alkoxy group with an electron-attracting group such as bromine or a trimethylammonium group, which lower the electronic density of the phosphorus atom, causes a strong increase in the rate of hydrolysis.

If the methyl group in Sarin is exchanged against a isopropoxy group, the rate is decreased $\left(k_{2}=0.831 \mathrm{~mole}^{-1} \text { sec. }{ }^{-1} \text { at } 25^{\circ} \mathrm{C}\right)^{1}$ which depends upon the increased mesomeric effect of the unshared electrons in the added oxygen atom. This effect is expected to be still greater in a dimethylamino group which is illustrated by the strong decrease in rate in the hydrolysis of bisdimethylamido-phosphoryl fluoride $\left(k_{2}=5.7 \times 10^{-5} 1 \mathrm{~mole}^{-1} \mathrm{sec}^{-1} \text { at } 25^{\circ} \mathrm{C}\right)^{27}$. The very strong decrease of the rate may also be attributed to the steric effect of the two dimethylamino groups.

As appears from Table 6 the activation energies of the reactions studied are approximately independent of the different substituents, even though some variations were expected. Similar results have been obtained in the alkaline hydrolysis of alkyl halides ${ }^{28}$. It is, however, essentially the free energy of activation which determines the rate of a reaction because the entropy of activation is not constant in the various reactions. The activation energy or really the heat of activation is rather to consider as an expression for the temperature dependence of the reaction.

From the results of the influence of the substituents on the rate of hydrolysis one can conclude that the rate of hydrolysis of Sarin and its analogues is mainly controlled by the strength of the P-F bond and by the ease with which the hydroxyl ion can attack the phosphorus atom. The approach of the hydroxyl ion depends upon the electronic density of the phosphorus atom, which is controlled by inductive and mesomeric effects of the substituents, and upon the steric hindrance by these substituents. The strength of the P-F bond is also influenced by the electron distribution of the substituents.

An attempt to a semi-quantitative treatment of the electrostatic effects of the substituents on the rates of hydrolysis has been performed on the basis of the theories improved by Kirkwood and Westheimer ${ }^{29}$, and their equations for charged substituents (5) and dipolar substituents (6) have been used in the computation of the rate constants:

$$
\ln k_{2}^{\prime \prime} / k_{2}=\frac{e^{2}}{k T D_{E} d}
$$

$$
\ln k_{2}^{\prime \prime} / k_{2}=\frac{e \mu \cos v}{\boldsymbol{k} T D_{E} d^{2}}
$$


where $k_{2}^{\prime \prime}$ is the rate constant of the substituted compound to be calculated and $k_{2}$ is the found rate constant of the unsubstituted compound.

The computations were made on the assumptions that the molecule was a sphere with the radius $R$, and that the oxygen atom of the hydroxyl ion in the transition state and the charged atom or the center of the dipole were placed equidistant from the center on a diameter of the sphere. The diameter, $2 R$, of the molecule was estimated from molecular models (Catalin Products Ltd.) as the geometric mean value of the lengths of three axes at right angles. The mean square distance, $d$, between the oxygen atom and the charged atom or the center of the dipole was calculated on the basis of free rotation about all the bonds ${ }^{29}$. The effective dielectric constant, $D_{E}$, is defined by the expression ${ }^{29}$ : $\mathrm{I} / D_{E}=f_{1} / D+f_{2} / D_{i}$, where $D$ is the dielectric constant of the medium, $D_{i}$ is the internal dielectric constant estimated as 2.0, and $f_{1}$ and $f_{2}$ are functions of the ratio $\frac{d}{2 R}$. The value $1.48 \times 10^{-18}$ e.s.u. was used for the dipole moment of the C-Br bond ${ }^{30}$, and the angle, $v$, between the dipole and the line joining it to the oxygen atom was estimated to $31^{\circ}$ from the fully extended molecule. Values of the angle found in this manner differ in general only little from those obtained from successive approximations ${ }^{31}$.

The calculated rate constants, $k_{2}^{\prime \prime}$, and the found rate constants, $k_{2}^{\circ}$, are given in Table 7. The found rate constants of the choline derivatives have been corrected to infinite dilution according to the theory of the influence of ionic strength on reactions between ions ${ }^{23 \mathrm{~b}}$. The computations from eqns. (6) and (5) of the rate constants, $k_{2}^{\prime \prime}$, of bromoethoxy-methyl-phosphoryl fluoride and of methyl-fluoro-phosphorylcholine are based on the rate constant, $k_{2}$, of ethoxy-methyl-phosphoryl fluoride. Those of the homocholine- and $\beta$-methylcholine-derivatives are analogously based on the rate constants of propoxy-methyl-phosphoryl fluoride and Sarin, respectively.

Table 7. The rate constants of the hydrolysis of 2-bromoethoxy-methyl-phosphoryl fluoride and the choline derivatives at $25^{\circ} \mathrm{C}$ calculated according to Kirkwood and Westheimer.



The calculated rate constants agree fairly well with the found ones. The discrepancies are mainly due to the low accuracy in the estimation of the distances $R$ and $d$ and the disregard of the influence of the substituents on the strength of the P-F bond. The relatively great discrepancy between the calculated and found rate constants of methyl-fluoro-phosphoryl- $\beta$-methylcholine is probably caused by no consideration being taken of the steric effect of the $\beta$-methyl group in the estimation of the distance $d$. To compensate for 
the steric effect of the trimethylammonium group the rate constant of methylfluoro-phosphorylcholine has also been calculated from the rate constant of 3,3-dimethylbutoxy-methyl-phosphoryl fluoride, at which calculation the logarithm of the rate constant was reduced from 3.84 to 3.75 . These results demonstrate that the employment of the theories of Kirkwood and Westheimer leads to reasonable values in the calculation of the rate constants of the hydrolysis of organo-phosphorus compounds.

My sincere thanks are due to Professor G. Ljunggren, Director of this Institute, for the kind interest he has shown in this work.

The author wishes also to express his sincere thanks to Docent L. Melander, Nobel Institute of Chemistry, for stimulating criticism and discussions.

\section{REFERENCES}

1. Kilpatrick, M. and Kilpatrick, M. L. J. Phys. \& Colloid Chem. 53 (1949) 1371, 1385.

2. Augustinsson, K.-B. Acta Chem. Scand. 6 (1952) 959.

3. Epstein, J., Rosenblatt, D. H. and Demek, M. M. J. Am. Chem. Soc. 78 (1956) 341.

4. Hackley, B. E., Plapinger, R., Stolberg, M. and Wagner-Jauregg, T. J. Am. Chem. Soc. 77 (1955) 3651.

5. Swidler, R. and Steinberg, G. M. J. Am. Chem. Soc. 78 (1956) 3594.

6. Green, A. L. and Saville, B. J. Chem. Soc. 19563887.

7. Epstein, J., Bauer, V. E., Saxe, M. and Demek, M. M. J. Am. Chem. Soc. 78 (1956) 4068.

8. Larsson, L. and Hansen, B. Svensk Kem. Tidskr. 68 (1956) 521.

9. Larsson, L., Holmstedt, B. and Tjus, E. Acta Chem. Scand. 8 (1954) 1563.

10. Tammelin, L.-E. Acta Chem. Scand. 11 (1957) 859.

11. Tammelin, L.-E. and Fagerlind, L. Unpublished results.

12. Ipatieff, V. N., Thompson, W. W. and Pines, H. J. Am. Chem. Soc. 73 (1951) 553.

13. Hennion, G. F. Ind. Eng. Chem., Anal. Ed. 9 (1937) 479.

14. Kinnear, A. M. and Perren, E. A. J. Chem. Soc. 19523437.

15. Augustinsson, K.-B. and Grahn, M. Acta Chem. Scand. 7 (1953) 906.

16. Hanes, C. S. and Isherwood, F. A. Nature 164 (1949) 1107.

17. Hack, M. H. Biochem. J. 54 (1953) 602.

18. Levine, C. and Chargaff, E. J. Biol. Chem. 192 (1951) 465.

19. Bates, R. G. Electrometric pH determinations. John Wiley \& Sons, Inc., New York 1954, pp. 74, 314.

20. Manov, G. G., Bates, R. G., Hamer, W. J. and Acree, S. F. J. Am. Chem. Soc. 65 (1943) 1765 .

21. Harned, H.S. and Owen, B. B. The Physical Chemistry of Electrolytic Solutions. Reinhold Publishing Corp., New York 1950, p. 381.

22. Guggenheim, E. A. Phil. Mag. 2 (1926) 538.

23. Glasstone, S., Laidler, K. J. and Eyring, H. The Theory of Rate Processes. McGrawHill Book Company, Inc., Now York 1941, a) p. 199, b) p. 428.

24. Larsson, L. Acta Chem. Scand. 7 (1953) 306.

25. Tammelin, L.-E. Acta Chem. Scand. 11 (1957). In press.

26. Dostrovsky, I. and Halmann, M. J. Chem. Soc. 19561004.

27. Heath, D. F. and Casapieri, P. Trans. Faraday Soc. 47 (1951) 1093.

28. Hinshelwood, C. N., Laidler, K. J. and Timm, E. W. J. Chem. Soc. 1938848.

29. Kirkwood, J. G. and Westheimer, F. H. J. Chem. Phys. 6 (1938) 506.

30. Ferguson, L. N. Electron Structures of Organic Molecules. Prentice-Hall, Inc., New York 1952, p. 133.

31. Westheimer, F. H. and Shockhoff, M. W. J. Am. Chem. Soc. 61 (1939) 555.

Received Mry 9, 1957. 